\title{
The effect of obesity and components of metabolic syndrome on urinary and sexual functions in Saudi men
}

This article was published in the following Dove Press journal:

Research and Reports in Urology

I8 April 2013

Number of times this article has been viewed

\author{
Hisham A Mosli \\ Hala $\mathrm{H}$ Mosli ${ }^{2}$ \\ Akram A Bokhari' \\ 'Department of Urology, ${ }^{2}$ Department \\ of Internal Medicine (Endocrinology), \\ King Abdulaziz University Hospital, \\ Jeddah, Saudi Arabia
}

Objective: To establish a possible association between obesity, measured by waist circumference (WC) and body mass index (BMI), and voiding and sexual functions in a random cohort of Saudi men.

Materials and methods: An outpatient men's health clinic was set up at King Abdulaziz University Hospital in Jeddah, Saudi Arabia and men were invited to discuss their sexual and urinary functions. The data collected included age, WC, weight, height, blood pressure, history of diabetes, hypertension, and smoking. The International Prostate Symptom Score (IPSS) and the International Inventory of Erectile Function (IIEF-5) questionnaire were used to assess urinary tract symptoms and sexual function, respectively. Serum testosterone, prostate-specific antigen and cholesterol levels were measured and documented. Data were analyzed using the Statistical Package for the Social Sciences.

Results: We recruited 113 participants. The mean WC and BMI of the men were $104 \pm 14.599 \mathrm{~cm}$ and $29.706 \mathrm{~kg} / \mathrm{m}^{2}$, respectively. Thirty-seven men (32.7\%) had an IPSS $\geq 8$ points. Sexual disorders were reported in 19 men; 16 men had erectile dysfunction, while three had premature ejaculation. Of the whole cohort, 37 men were diabetic, of which $15(40.5 \%)$ had an IPSS $\geq 8$ and $13(35 \%)$ were either overweight or obese.

Conclusion: Increased WC and BMI were associated with diabetes mellitus and large percentages of voiding and sexual disorders.

Keywords: obesity, waist circumference, body mass index, voiding function, sexual function

\section{Introduction}

Recent literature supports the finding that metabolic syndrome, in particular central obesity, has an impact on male sexual function. ${ }^{1}$ Obesity, represented by an increase in waist circumference (WC) or body mass index (BMI), has also been reported to have a similar deleterious effect on voiding in men., ${ }^{2,3}$ In addition to aging, lack of physical activities, erectile dysfunction, and a family history of benign prostatic hypertrophy $(\mathrm{BPH})$, obesity has recently emerged to be regarded as a significant factor among the risk factors for BPH. ${ }^{1-3}$ The World Health Organization (WHO) declared obesity as a worldwide epidemic as of $2007 .{ }^{4}$ Along with other countries in both the east and west, the Saudi Arabia (SA) is a population plagued with obesity, with the age-adjusted prevalence of obesity documented at $35.5 \% .^{4-6}$ In addition to obesity, type 2 diabetes mellitus, ${ }^{7}$ hypertension, ${ }^{8}$ and hypercholesterolemia ${ }^{9}$ were all reported to be common in SA along with metabolic syndrome in its full blown picture. ${ }^{10}$ In this prospective study we aimed to establish the effect of obesity and components of metabolic syndrome on urinary and sexual functions in a cohort of Saudi men.
Correspondence: Hisham A Mosli King Abdulaziz University Hospital, PO Box 80215, Jeddah 21589,

Saudi Arabia

Tel $+96650558 \quad 1520$

Fax +96626761272

Email hmosli@hotmail.com
Research and Reports in Urology 2013:5 91-97

(c) 2013 Mosli et al, publisher and licensee Dove Medical Press Ltd. This is an Open Access article Dovepress 


\section{Materials and methods}

An outpatient men's health clinic was set up at a tertiary referral center at King Abdulaziz University Hospital, Jeddah, Saudi Arabia. Men were invited by way of public advertisement to visit the clinic to discuss their sexual and urinary functions. Participants were included on a consecutive basis. All participants signed an informed consent prior to inclusion in the study. The study was approved by the institution's ethics research committee. Inclusion criteria were adult men with urinary and/or sexual dysfunction. No exclusion criteria were set.

For all participants enrolled in this prospective study, we collected details about their sociodemographic characteristics. We also recorded WC (at the end of several consecutive natural breaths, at a level parallel to the floor, midpoint between the top of the iliac crest, and at the lower margin of the last palpable rib in the midaxillary line); weight; height; BMI, blood pressure (BP) readings; lower urinary tract symptoms as measured using the Arabic version of the International Prostate Symptom Score (IPSS); ${ }^{11}$ and testosterone; serum prostate-specific antigen (PSA); glycosylated hemoglobin ( $\left[\mathrm{HbA}_{1 \mathrm{c}}\right]$ in participants with diabetes); and cholesterol levels. Due to cultural considerations, a number of participants declined physical measures such as WC. Participants with complete measurements were analyzed separately. BMI was calculated according to the internationally accepted equation as BMI $=$ weight (in kilograms) divided by the height squared (in meters). Sexual function was assessed by the simplified International Index of Erectile Function (IIEF-5) questionnaire. ${ }^{12}$

Men were classified into three groups according to their WC: normal if $\leq 90 \mathrm{~cm}$, moderate if $90-99 \mathrm{~cm}$, and severely increased if $\geq 100 \mathrm{~cm}^{2}$ We also grouped the participants in four categories based on the WHO classification: underweight if $\mathrm{BMI} \leq 18.50 \mathrm{~kg} / \mathrm{m}^{2}$; normal weight if BMI $=18.50-24.9 \mathrm{~kg} / \mathrm{m}^{2}$; overweight if BMI $\geq 25 \mathrm{~kg} / \mathrm{m}^{2}$; and obese if $\mathrm{BMI} \geq 30 \mathrm{~kg} / \mathrm{m}^{2}{ }^{4}$

Men were considered to have voiding symptoms if they had $\geq 8$ points on the IPSS. They were considered to have sexual disorders, including erectile dysfunction and premature ejaculation, if they had $\leq 22$ points on the IIEF-5.

\section{Statistical analysis}

Statistical analysis was performed using the Statistical Package for the Social Sciences Version 16 ([SPSS] IBM Corporation, Armonk, NY, USA). For numerical variables, descriptive statistics was performed and the results were expressed as mean \pm standard deviation (SD). Pearson correlation was used for normally distributed variables (serum testosterone and BMI). The relationship between serum testosterone and BMI was assessed by linear regression. For categorical values, descriptive statistics was performed and the results were expressed as frequencies and percentages. Fisher's exact test was used if the assumptions of chi-squared testing were not met $(>20 \%$ of the cells had an expected value $<5)$. A $P$-value $<0.05$ was considered significant.

\section{Results}

One hundred thirteen men volunteered to enroll in this study. The mean \pm SD age of the participants was $44.90 \pm 12.42$ years (range, 20-73 years). The WC was measured for 73 men. The mean WC in our study population was $104 \pm 14.59 \mathrm{~cm}$ (range, $62-143 \mathrm{~cm}$ [24.8-57.2 inches]). Only 12 men (16\%) had WC of $90 \mathrm{~cm}$ or less; another 12 men (16\%) had WC between 90 and $100 \mathrm{~cm}$. Most men $(\mathrm{n}=49,68 \%)$ had a $W C \geq 100 \mathrm{~cm}$.

The weight and height were recorded for $78 \mathrm{men}$. The mean weight was $85.62 \pm 17.38 \mathrm{~kg}$ (range, $56.1-148.0 \mathrm{~kg}$ ), while the mean height was $169.83 \pm 6.05 \mathrm{~cm}$ (range between 162$180 \mathrm{~cm}$ ). The mean BMI of the men was $29.71 \mathrm{~kg} / \mathrm{m}^{2}$ (range, $\left.19.1-50.1 \mathrm{~kg} / \mathrm{m}^{2}\right)$. Most men, 63 of $78(80.8 \%)$, were either overweight $(n=27,34.6 \%)$ or obese $(n=36,46.2 \%)$. The WC measurements and BMI categories are summarized in Table 1.

There was a positive correlation between the $\mathrm{WC}$ and BMI as shown in Table 2.

BP was measured for 76 men. The mean systolic BP was $133.43 \pm 16.17 \mathrm{mmHg}$ and the mean diastolic BP was $77.66 \pm 13.31 \mathrm{mmHg}$ (normal range, systolic $=120 \mathrm{mmHg}$ and diastolic $=80 \mathrm{mmHg}$ ).

Of the 113 men who participated in the study, 37 men $(32.7 \%)$ had an IPSS $\geq 8$ points.

The mean serum PSA was $1.02 \pm 0.62 \mathrm{ng} / \mathrm{mL}$ (reference range, $0.00-4 \mathrm{ng} / \mathrm{mL}$ ) for 63 men in whom the test was performed.

Table I Waist circumference (WC) and body mass index (BMI) distribution in the study cohort

\begin{tabular}{llllll}
\hline WC measurement & Frequency $(\mathbf{n})$ & Percent & BMI category & Frequency (n) & Percent \\
\hline$\leq 90 \mathrm{~cm}$ & 12 & 16 & Normal weight & 15 & 19.2 \\
$90-100 \mathrm{~cm}$ & 12 & 16 & Overweight & 27 & 34.6 \\
$\geq 100 \mathrm{~cm}$ & 49 & 68 & Obese & 36 & 46.2 \\
Total & 73 & 100 & Total & 78 & 100.0 \\
\hline
\end{tabular}

Abbreviation: $n$, number. 
Table 2 Relationship between waist circumference (WC) and body mass index (BMI) in the study cohort

\begin{tabular}{lll}
\hline BMI & BMI & WC \\
Pearson correlation & & \\
Significance (two-tailed) & $\mathrm{I}$ & $0.84^{*}$ \\
Number of participants & & 0.00 \\
WC & 78 & 73 \\
Pearson correlation & & \\
Significance (two-tailed) & $0.84^{*}$ & $\mathrm{I}$ \\
Number of participants & 0.00 & \\
\hline
\end{tabular}

Note: $* P$-value $<0.05$ was considered significant.

Sexual function was assessed in 68 men, 19 of whom had sexual disorders (16 had erectile dysfunction with IIEF-5 $\geq 22$ points, and three had premature ejaculation).

Morning serum testosterone level was measured in $57 \mathrm{men}$; the mean value was $14.14 \pm 5.38 \mathrm{mmol} / \mathrm{L}$ (reference range, $9.1-55.2 \mathrm{mmol} / \mathrm{L})$. There was a progressive and steep decline in testosterone level as the BMI increased (Figure 1). A similar relationship was seen between serum testosterone level and WC (Figure 2).

Thirty-seven men (32.7\%) were diabetic, 12 (10.6\%) had a history of diabetes, while incident diabetes (fasting blood glucose $\geq 7.0 \mathrm{mmol} / \mathrm{L})$ was diagnosed in 25 men $(22.1 \%)$. The mean $\mathrm{HbA}_{1 \mathrm{c}}$ level in the diabetic men was $8.1 \%$ (reference range, $4.8 \%-6.0 \%)$. Of the diabetic men, $15(40.5 \%)$ had an IPSS $\geq 8$ and $13(35 \%)$ were either overweight or obese.
The cholesterol level was measured for 66 men. The mean total cholesterol level was $5.38 \pm \mathrm{SD} 6.02 \mathrm{mmol} / \mathrm{L}$ (reference range, $0.00-5.20 \mathrm{mmol} / \mathrm{L})$.

\section{Discussion}

Key findings of this current study include the association between obesity, metabolic syndrome, diabetes mellitus type 2 , and voiding and sexual dysfunctions in a sample of the local population in Saudi Arabia.

Saudi Arabia is one of the fastest economically growing countries. Nonetheless, affluence associated with prosperity has resulted in some serious health problems due to overindulgence in the consumption of high-calorie foods and intake of excessive amounts of fast and fatty food. Obesity follows with all its metabolic sequences, especially when living circumstances preclude the performance of preventive regular physical activities. In 2005, it was reported that $35.5 \%$ of the Saudi Population was obese $\left(\mathrm{BMI}>30 \mathrm{~kg} / \mathrm{m}^{2}\right) .{ }^{5}$ In a more recent report, $37.9 \%$ and $28.3 \%$ males were reported to be overweight $\left(\mathrm{BMI} \geq 25 \mathrm{~kg} / \mathrm{m}^{2}\right)$ and obese $\left(\mathrm{BMI} \geq 30 \mathrm{~kg} / \mathrm{m}^{2}\right)$, respectively. ${ }^{6}$ Obesity is the cornerstone among the cluster of risk factors that constitute metabolic syndrome, namely hypertension, diabetes, and dyslipidemia. ${ }^{13}$ Hypertension, which is linked to obesity, is also prevalent is Saudi Arabia. It affects over one-quarter of the Saudi adult population. ${ }^{9}$ In one report, it was shown that increases in weight were accompanied by an increase in the prevalence of hypertension. ${ }^{9}$

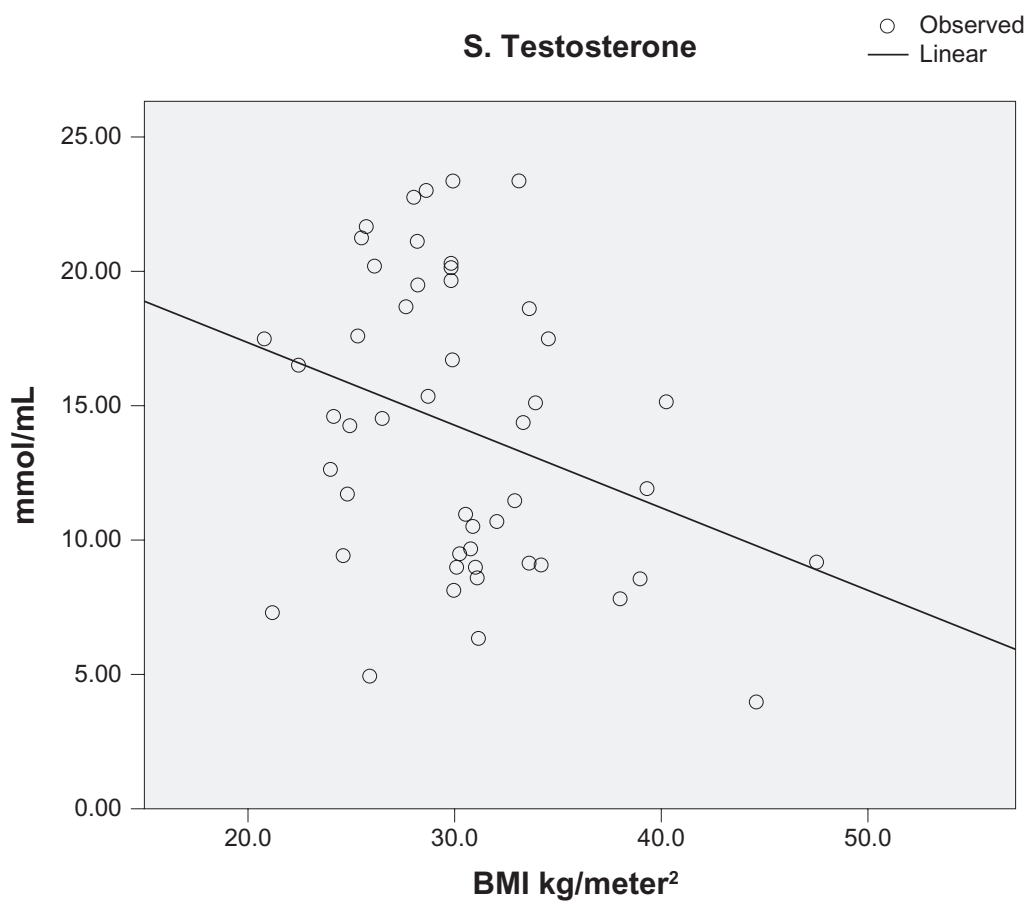

Figure I Scatter plot showing the relationship between serum testosterone levels and the different body mass index (BMI) categories in the study cohort. 


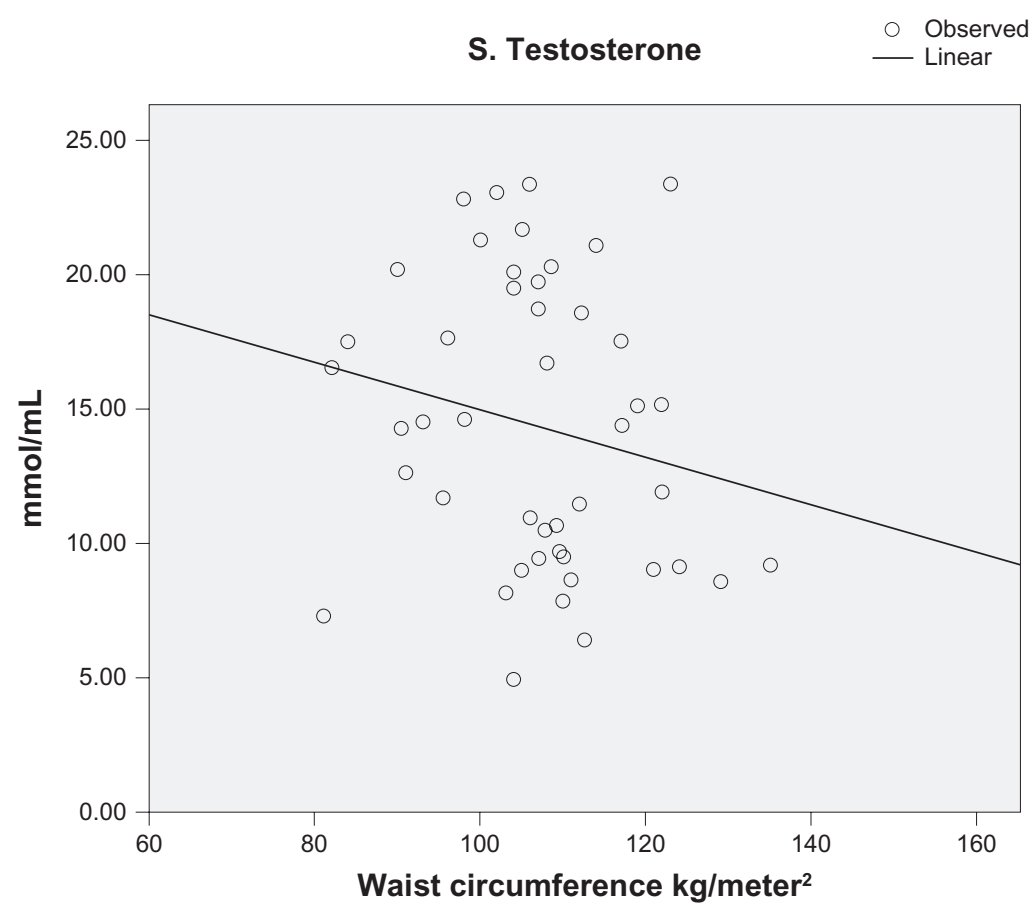

Figure 2 Scatter plot showing the relationship between serum testosterone levels and waist circumference measurements in the study cohort.

In our study, the mean $\mathrm{WC}$ of the participants was severely increased compared to normal men with a WC less than $90 \mathrm{~cm}$ (mean of $104 \pm 14.59 \mathrm{~cm}$ ). Studies in Middle Eastern populations have provided WC and waist-hip ratio cutoff points similar to those suggested for Europeans, with a waist circumference of more than $102 \mathrm{~cm}$ in men being associated with substantially increased risk of metabolic complications. ${ }^{14}$ Mean BMI was at the upper limit of the overweight category (approaching the obese category). Therefore, voiding and sexual disorders of some magnitude are to be anticipated in such a population.

The overall prevalence of diabetes mellitus in adults in SA is $23.7 \% ;^{7}$ this rate, as well as the prevalence of obesity, is higher in our study population, possibly because of selection bias given that the advertisement was targeted at men with concerns of voiding or sexual dysfunctions. Recently, it was reported that the prevalence of hypercholesterolemia (levels between 5.2 and $6.2 \mathrm{mmol} / \mathrm{L}$ ) in Saudi Arabia was 9\% and $11 \%$ for males and females, respectively $(P=0.74)$. The prevalence was $7 \%$ and $8 \%$ for males and females, respectively, when cutoff values of $\geq 6.2$ were used to define hypercholesterolemia $(P=0.52){ }^{9}$ For cutoff values between 5.2 and $6.2 \mathrm{mmol} / \mathrm{L}$, the prevalence of hypercholesterolemia for those aged $40-59$ years was $14 \%$ and $10 \%$ for males and females, respectively $(P=0.67)$, whereas at values of $>6.2 \mathrm{mmol} / \mathrm{L}$, the prevalence was $9 \%$ and $11 \%$ for males and females, respectively $(P=0.6){ }^{9}$ In the current study, the measurement of cholesterol levels was included to examine any possible association between hypercholesterolemia and voiding and sexual dysfunctions; however, none was found.

Besides other associated conditions, such as physical inactivity, aging, and hormonal imbalance, the predominant underlying risk factors for metabolic syndrome appear to be abdominal obesity and insulin resistance. ${ }^{13,15}$ This may explain why the prevalence of metabolic syndrome was reported to be high in Saudi Arabia, with an overall ageadjusted prevalence rate of $39.3 \%$ for both sexes. ${ }^{10}$ The main concern with metabolic syndrome involves the cardiovascular diseases, mainly coronary artery disease, as this is a leading cause of death. ${ }^{15}$ These links are illustrated in Figure 3.

Obesity is measured by several methods, but for practical purposes and simplicity, it is represented in clinical urology by WC or BMI. ${ }^{2}$ Recent data suggested a relationship between $\mathrm{WC}$ and health parameters, mainly diabetes, hypertension, prostate volume (PV), and voiding and sexual dysfunctions. ${ }^{2}$ In addition, a recent study linked metabolic syndrome with intraprostatic inflammation, suggesting that it could be an important factor in the development and progression of benign prostatic hyperplasia (BPH). ${ }^{16}$ Furthermore, in an experimental study, testosterone was reported to protect from metabolic syndrome-associated prostate inflammation. ${ }^{17}$ The findings of the current study are in line with these data: almost one-third of the group of volunteering men - the majority with increased WC and BMI - had voiding dysfunction, and over one-tenth 


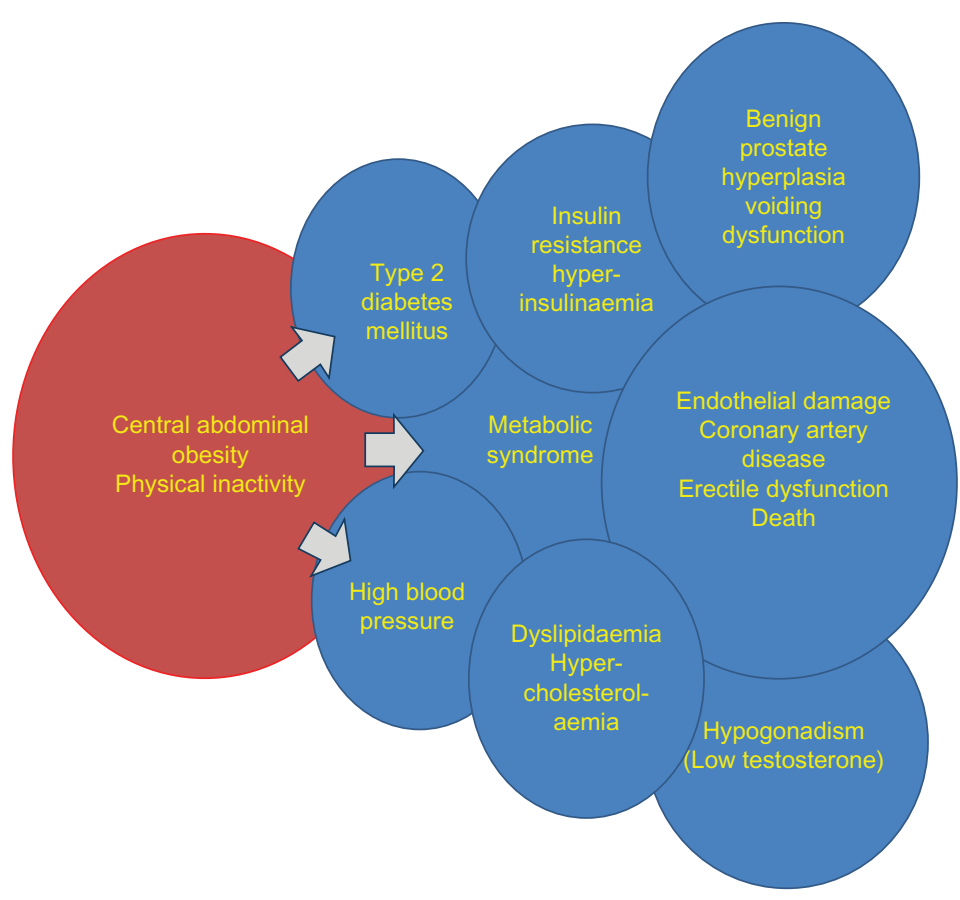

Figure 3 The links between obesity and affected health parameters.

had sexual dysfunction. Therefore, our local populations, as well as other similar overweight and obese populations, are expected to develop many of these health problems.

Diabetes mellitus has been extensively discussed as a risk factor for many urological disorders, mainly voiding and sexual dysfunctions. ${ }^{18}$ Furthermore, there is evidence that type 2 diabetes mellitus is associated to, linked to, or even a direct sequel of obesity through the development of insulin resistance. ${ }^{18,19}$ The resultant hyperinsulinemia ${ }^{19}$ plays a major role in the pathophysiological changes that occur in the genitourinary system and throughout the whole human body, as shown in Figure 3.

Sexual dysfunction, including erectile dysfunction and premature ejaculation, is thought to be precipitated by several known risk factors, of which most are linked to obesity in one way or another. ${ }^{20}$ Several studies have reported a clear link between metabolic syndrome and both erectile dysfunction and hypogonadism. ${ }^{21-23}$ Similar findings were observed in our study population.

Evidence from a large prospective study indicates that a progressive increase in BMI is associated with progressive increase in PV and attenuated response to treatment with 5-alpha reductase inhibitors. ${ }^{24-26}$ In our opinion, this finding has important relevant therapeutic implications in the medical treatment of obese men with BPH. This also warrants further research studies on the relationship between the degree of obesity and unresponsiveness to medical therapy and the development of complications of $\mathrm{BPH}$, such as retention of urine.

With the rapid escalation of rates of obesity and metabolic syndrome worldwide, a steady rise in the incidence of voiding and sexual dysfunctions in men with large WC or high BMI should be expected. ${ }^{27-30}$

Recent guidelines from the American Urological Association and the European Association of Urology do not include obesity among the risk factors nor do the treatment guidelines include adequate weight reduction in addition to life style modifications for erectile dysfunction, BPH, or voiding dysfunction, and neither do these guidelines mention the management of sexual and urinary disorders in obese patients. ${ }^{31-33}$ Findings from our study prompt us to believe that obesity should be considered as a major risk factor for many urological and non-urological diseases, and hence a major public health concern. The documentation of WC and calculation of BMI should be among the initial steps in the clinical evaluation of urological patients, similar to measurement of heart rate and BP. Weight reduction and encouragement for physical activity should be discussed with all overweight and obese patients in the clinical setting before discussing options for medical treatment and surgical procedures. We suggest incorporating protective weight reduction to ideal weights and physical exercises to maintain fitness in the different algorithms for the evaluation and management of BPH and voiding and sexual dysfunctions. 
Although comprehensive and of broad spectrum, this study had some limitations in that the sample size was small and that data could not be obtained for all the participants owing to the voluntary nature of the study. Moreover, because the study was not funded, our resources did not enable us to obtain data for all the participants. Nevertheless, the findings of this study are in line with those of other studies, indicating the need for urologists to be aware of the negative impact of obesity on men's sexual and urinary functions.

\section{Conclusion}

The current study examined the effects of obesity and components of metabolic syndrome on the voiding and sexual functions in a random cohort of Saudi men who were concerned about their voiding and erectile functions. In a population characterized by prevalent rates of obesity and overweight, increased percentages of men with voiding and sexual dysfunctions in addition to diabetes mellitus were observed compared to normal weight volunteers. While there was no significant correlation between obesity and PSA levels, testosterone levels declined with increases in WC and BMI.

\section{Disclosure}

The authors report no conflicts of interest in this work.

\section{References}

1. Hammarsten J, Peeker R. Urological aspects of the metabolic syndrome. Nat Rev Urol. 2011;8(9):483-494.

2. Lee RK, Chung D, Chughtai B, Te AE, Kaplan SA. Central obesity as measured by waist circumference is predictive of severity of lower urinary symptoms. BJU Int. 2012;110:540-545.

3. Kaplan S, Fisch H, Berriman SJ. Central obesity as measured by waist circumference is predictive of severity of lower urinary tract symptoms, sexual dysfunction, and components of the metabolic syndrome [abstract 1508]. J Urol. 2007;177(4suppl):497-498.

4. Global Database on Body Mass Index: an interactive surveillance tool for monitoring nutrition transition [webpage on the Internet]. Geneva: World Health Organization; 2006 [updated March 25, 2013]. Available from: http://apps.who.int/bmi/index.jsp. Accessed August 22, 2012.

5. Al-Nozha MM, Al-Mazrou YY, Al-Maatouq MA, et al. Obesity in Saudi Arabia. Saudi Med J. 2005;26:824-829.

6. Ng SW, Zaghloul S, Ali HI, Harrison G, Popkin BM. The prevalence and trends of overweight, obesity and nutrition-related non-communicable diseases in the Arabian Gulf States. Obes Rev. 2011;12(1):1-13.

7. Al-Nozha MM, Al-Maatouq MA, Al-Mazrou YY, et al. Diabetes mellitus in Saudi Arabia. Saudi Med J. 2004;25(11):1603-1610.

8. Al-Nozha MM, Abdullah M, Arafa MR, et al. Hypertension in Saudi Arabia. Saudi Med J. 2007;28(1):77-84.

9. Kumosani TA, Alama MN, Iyer A. Cardiovascular diseases in Saudi Arabia. Prime Research on Medicine. 2011;1:1-6.

10. Al-Nozha M, Al-Khadra A, Arafah MR, et al. Metabolic syndrome in Saudi Arabia. Saudi Med J. 2005;26(12):1918-1925.
11. Mosli HA, Farsi HMA, Al-Zimaity MF. Evaluation of a symptom score index for measurement of lower urinary symptoms in Arabic form. Saudi Med J. 1995;16(6):536-542.

12. Rhoden EL, Telöken C, Sogari PR, Vargas Souto CA. The use of the simplified International Index of Erectile Function (IIEF-5) as a diagnostic tool to study the prevalence of erectile dysfunction. Int J Impot Res. 2002;14:245-250.

13. Grundy SM, Cleeman JI, Daniels SR, et al; American Heart Association; National Heart, Lung, and Blood Institute. Diagnosis and management of the metabolic syndrome: An American Heart Association/National Heart, Lung and Blood Institute Scientific Statement. Circulation. 2005; 112(17):2735-2752.

14. World Health Organization. Waist Circumference and Waist-Hip Ratio Report of a WHO Expert Consultation, Geneva, 8-11 December 2008.

15. Grundy SM. Obesity, metabolic syndrome, and cardiovascular disease. J Clin Endocrinol Metab. 2004;89(6):2595-2600.

16. Gacci M, Vignozzi L, Sebastianelli A, et al. Metabolic syndrome and lower urinary tract symptoms: the role of inflammation. Prostate Cancer Prostatic Dis. 2013;16(1):101-106.

17. Vignozzi L, Morelli A, Sarchielli E, et al. Testosterone protects from metabolic syndrome-associated prostate inflammation: an experimental study in rabbit. $J$ Endocrinol. 2012;212(1):71-84.

18. Gao Y, Wang M, Zhang H, et al. Are metabolic syndrome and its components associated with lower urinary tract symptoms? Results from a Chinese male population survey. Urology. 2012;79:194-201.

19. Hammarsten J, Högstedt B. Hyperinsulinaemia as a risk factor for developing benign prostatic hyperplasia. Eur Urol. 2001;39:151-158.

20. Saad F, Gooren LJ. The role of testosterone in the etiology and treatment of obesity, the metabolic syndrome, and diabetes mellitus type 2 . J Obes. 2011;2011:Article ID 471584.

21. Guay AT. The emerging link between hypogonadism and metabolic syndrome. J Androl. 2009;30:370-376.

22. Mulligan T, Frick MF, Zuraw QC, Stemhagen A, McWhirter C. Prevalence of hypogonadism in males aged at least 45 years: the HIM study. Int J Clin Pract. 2006;60(7):762-769.

23. El-Sakka AI, Tayeb KA. Erectile dysfunction risk factors in noninsulin dependent diabetic Saudi patients. J Urol. 2003;169:1043-1047.

24. Kaplan S, Wilson TW. Association between BPH and the metabolic syndrome in the REDUCE population [abstract 1548]. J Urol. 2007; 177(4 suppl):511.

25. Muller R, Gerber L, Moreira D, et al. Obesity is associated with increased prostate growth and attenuated prostate volume reduction by dutasteride. Poster No 1736. AUA Annual Meeting 2012 May 19-23; Atlanta, GA, USA.

26. Lee SH, Oh CY, Park KK, Chung MS, Yoo SJ, Chung BH. Comparison of the clinical efficacy of medical treatment of symptomatic benign prostatic hyperplasia between normal and obese patients. Asian JAndrol. 2011;13:728-731.

27. Parsons JK, Sarma AV, McVary K, Wei JT. Obesity and benign prostatic hyperplasia: clinical connections, emerging etiological paradigms and future directions. J Urol. 2009;182:S27-S31.

28. Ozden C, Ozdal OL, Urgancioglu G, Koyuncu H, Gokkaya S, Memis A. The correlation between metabolic syndrome and prostatic growth in patients with benign prostatic hyperplasia. Eur Urol. 2007;51: 199-203.

29. Keto CJ, Maska EM, Freedland SJ. Physical Activity, Obesity, and Lower Urinary Tract Symptoms. Eur Urol. 2011;60:1181-1183.

30. De Nunzio C, Aronson W, Freedland SJ, Giovannucci E, Parsons JK. The correlation between metabolic syndrome and prostatic diseases. Eur Urol. 2012;61(3):560-570.

31. AUA Clinical Practice Guidelines [updated Sep 2010]. Available from: http:/www.auanet.org/content/clinical-practice-guidelines/ clinical-guidelines/main-reports/bph-management/final_appendices. pdf. Accessed August 22, 2012. 
32. AUA Guideline on the Management of Erectile Dysfunction: Diagnosis and Treatment Recommendations. American Urological Association Education and Research, Inc; 2005. Available from: http://www. auanet.org/content/clinical-practice-guidelines/clinical-guidelines/ main-reports/edmgmt/chapter1.pdf. Accessed August 22, 2012.
33. www.uroweb.org [webpage on the Internet]. European Association of Urology. Available from: http://www.uroweb.org/gls/pdf/14_Male\%20 Sexual\%20Dysfunction_LR.pdf. Accessed August 22, 2012.

\section{Publish your work in this journal}

Research and Reports in Urology is an international, peer-reviewed, open access journal publishing original research, reports, editorials, reviews and commentaries on all aspects of adult and pediatric urology in the clinic and laboratory including the following topics: Pathology, pathophysiology of urological disease; Investigation and treatment of

\section{Dovepress}

urological disease; Pharmacology of drugs used for the treatment of urological disease. The manuscript management system is completely online and includes a very quick and fair peer-review system, which is all easy to use. Visit http://www.dovepress.com/testimonials.php to read real quotes from published authors.

Submit your manuscript here: http://www.dovepress.com/research-and-reports-in-urology-journal 